\title{
Evolutionary Game of User Knowledge Sharing Behaviors in Enterprise Brand Virtual Community: Influence of Multiple Level Factors
}

\author{
Chengyi Le, Peipei Li, Ya Zeng \\ School of Economics and Management, East China Jiaotong University, Nanchang, China \\ Email: ncycy@126.com
}

How to cite this paper: Le, C. Y., Li, P. P., \& Zeng, Y. (2021). Evolutionary Game of User Knowledge Sharing Behaviors in Enterprise Brand Virtual Community: Influence of Multiple Level Factors. Journal of Human Resource and Sustainability Studies, 9, 1-19. https://doi.org/10.4236/jhrss.2021.91001

Received: January 6, 2021

Accepted: January 31, 2021

Published: February 3, 2021

Copyright $\odot 2021$ by author(s) and Scientific Research Publishing Inc. This work is licensed under the Creative Commons Attribution International License (CC BY 4.0).

http://creativecommons.org/licenses/by/4.0/

\begin{abstract}
The exchange and sharing of user knowledge in the brand virtual community is an important way for enterprise product innovation. Therefore, how to encourage users to share their knowledge continuously in the brand virtual community is a key issue. Based on evolutionary game theory, this paper analyzes the influence of various factors on user's knowledge sharing behavior from the aspects of individual factors, mutual factors and community factors. Through simulation, it is found that there exist two evolutionary stability strategies, that is, (knowledge sharing, knowledge sharing) and (no knowledge sharing, no knowledge sharing). And which direction this system evolves depends on the initial probability and critical points of knowledge sharing. Results show that user's knowledge level in individual level, the ability to transform and absorb knowledge, the degree of knowledge sharing, the innovation degree of knowledge sharing and the incentive coefficient in community level have a positive impact on the user's knowledge sharing behavior. Meanwhile, the cost of knowledge sharing between individuals, the homogeneity of knowledge and the spillover effect in mutual level have a negative impact on the behavior of user knowledge sharing. What's more, there is an optimal coefficient of collaborative profit distribution, which makes the system most likely to evolve in the direction of (knowledge sharing, knowledge sharing).
\end{abstract}

\section{Keywords}

Brand Virtual Community, Knowledge Sharing, Evolutionary Game, Support Strategy

\section{Introduction}

In the era of complex and fast-changing knowledge economy, for various indus- 
tries, innovation is the foundation of survival and development in such a fiercely competitive environment. Therefore, many enterprises, such as ZTE, Lenovo, Haier, Huawei, Xiaomi (Li et al., 2019; Meng et al., 2019; Meng et al., 2018) and so on, have established brand virtual communities which have the advantage of gathering public wisdom and brainstorming. A brand virtual community refers to an online platform established by an enterprise to share knowledge and exchange knowledge between users and internal employees who are interested in products. With the help of brand virtual communities, they can achieve product innovation through internal and external cooperation, and create a good brand image (Liao et al., 2017; Zhang \& Li, 2017). At present, due to the knowledge sharing of brand virtual community users, Xiaomi has realized their purpose of product innovation. For example, Xiaomi established the MIUI forum to share knowledge with users which has promoted the successful development of the company's core product, MIUI system (Yan et al., 2019). Obviously, the establishment of brand virtual communities and the knowledge sharing of users play a vital role in product innovation (Zheng et al., 2018; Wirtz et al., 2013).

Although the number of brand virtual communities is still increasing, relevant data shows that about half of brand virtual communities do not work effectively (Porter et al., 2011). At present, with the continuous development of virtual communities, it has exposed a series of problems such as users' low willingness to participate in knowledge sharing, low knowledge sharing (Gu et al., 2019), etc. Almost $90 \%$ of users in virtual communities basically do not contribute, while $9 \%$ of users occasionally contribute, and only $1 \%$ of users often contribute (Jakob, 2014; Nielsen, 2006). The brand virtual communities established by enterprises also have these problems. For example, the ZTE community, which already has 4.6 million users by 2019 , only has about 770,000 posts. As for the posts in Huawei product community, the number of views is always much higher than the number of comments, and the number of suggestions actually adopted by enterprises is relatively small. These problems hinder the development of existing brand virtual communities and greatly reduce the utility of user knowledge sharing on product innovation.

In summary, only by solving these problems faced by brand virtual communities can we promote the steady development of brand virtual communities, the continuous knowledge sharing behavior of users and help enterprises achieve product innovation by introducing external resources. Therefore, by exploiting evolutionary game method, this paper takes users as the game object, analyzes the influence of various factors of a brand virtual community on user knowledge sharing behavior, depicts the evolution process of user knowledge sharing behavior, and provides theoretical basis for finding the best evolution strategy.

The remainder of this paper is organized as follows. Section 2 reviews a selection of relevant literature informing the research questions and the design of the research approach. In Section 3, an evolutionary game model is established to study user knowledge sharing behavior in an enterprise brand virtual community, and we analyze the evolutionary stability point in four different situations. 
Section 4 includes a numerical simulation with an analysis of the results. Finally, conclusions and implications are offered in Section 5.

\section{Literature Review}

Many scholars have focused on the research of the related areas about knowledge sharing in virtual communities. Park and Gabbard (2018) examined the factors that affect knowledge sharing behavior in health and life sciences research communities, and found that reciprocal benefit, fear of being scooped, reputation and anticipated relationship were significant in affecting knowledge sharing behavior, but altruism showed no main effects on knowledge sharing (Park \& Gabbard, 2018). Hwang et al. (2018) explored the effect of personal information management motivation on users' commitment to knowledge systems, and the survey results of 78 accounting professionals demonstrated that information formality has the strongest effect on knowledge sharing motivation (Hwang et al., 2018). Zhao et al. (2017) studied user knowledge sharing behavior from the user's motivation, and finally found that the problem-solving motivation was the user's initial knowledge sharing motivation, and the altruistic motivation and hedonic motivation were new added motivations in the continuous knowledge sharing process (Zhao et al., 2017); Shang and Zhang (2015) constructed an evolutionary game model of knowledge sharing among members in virtual enterprise, and the results confirmed that the degree of trust between members and the complementarity of knowledge will increase the willingness of members to share knowledge, and the cost of knowledge sharing will reduce the willingness of team members to share knowledge (Shang \& Zhang, 2015); Zhang et al. (2019) found that network density, shared language, and shared vision of social capital had a positive influence on knowledge-sharing in Virtual Brand Communities (Zhang et al., 2019). Han et al. (2019) developed an object model that reflects the dynamics of knowledge and found that direct experience can affect consumers' self-efficacy to promote knowledge sharing in online brand communities (Han et al., 2019). Cassandra et al. (2018) constructed a new four-dimensional co-creation behavior concept from the customer-level and brand-level, and verified that category participation, brand participation, brand self-consistency, brand community, and brand interaction had an impact on customer brand co-creation behavior and perceived value (Cassandra et al., 2018). Shen and Li (2018) conducted an online survey with 480 respondents in one of the largest online brand communities in Mainland China, and the findings revealed that both complementary fit and supplementary fit positively affect customers' intrinsic and extrinsic motivations, which further significantly enhances knowledge contribution intention in virtual brand community (Shen \& Li, 2018). Li et al. (2018) explored the indirect effect of interpersonal relationship motivation on members' knowledge sharing behaviors, which is significantly strong based on effort and attribution theory (Li et al., 2018).

Evolutionary game theory combines game analysis and evolution dynamics 
organically, and examines economic phenomena based on bounded rationality, which is able to explain the longer-term economic and trading relationships between a large number of individuals. It believes that individuals cannot make a decision to maximize their own interests through a single game, and they need to continuously adjust and improve their own strategies in the process and finally evolve to a stable strategy (Shen \& Chen, 2019; Tian et al., 2014; Zhang et al., 2018). There are many articles using evolutionary game theory to study user' knowledge sharing behavior. Li and Kang (2019) constructed an evolutionary game model that demonstrates a long-term strategy for supply chain partners towards knowledge sharing is determined through reaching an equilibrium between enabling factors (revenue gained in various forms) and impeding factors (knowledge leakage) in a dynamic process (Li \& Kang, 2019). Liu and Liu (2019) extended the research on the reciprocal cooperation of knowledge team from the perspective of behavioral economics, and it showed that the proportion of initial reciprocal actors, the proportion of sharing, and the degree of knowledge complementation are all conducive to the formation of reciprocal cooperation of knowledge transfer, while the work conflict is just the opposite ( $\mathrm{Liu} \& \mathrm{Liu}$, 2019). Jiang et al. (2014) considered the interaction between community users and constructed an evolutionary game model of user knowledge sharing behavior and the results showed that the network structure formed between users has a significant impact on the evolution level of knowledge sharing (Jiang et al., 2014). Hao et al. (2019) established the game model of knowledge sharing between the members of the alliance under trust and without trust mechanism, and analyzes and compares the dynamic evolution mechanism of knowledge sharing behavior between members in these two cases (Hao et al., 2019). Cheng et al. (2018) researched a game model of user adoption behavior in the stage of service negotiation and service use, and it was found that user's behavior will be adjusted and changed in different stages (Cheng et al., 2018). Hou, Wang, \& Yang (2017) constructed the evolutionary game model of knowledge transformation and sharing in online health community users based on SECI model and analyzed different strategies to improve knowledge transformation efficiency (Hou et al., 2017). Chen et al. (2018) investigated how the chosen pricing model (wholesale pricing model or agency pricing model) affects the online retailer's profit, industry profit, consumer surplus, and social welfare (Chen et al., 2018). Xiao et al. (2020) established one centralized contract and three decentralized contracts, namely wholesale price contract, revenue-sharing contract, and costsharing contract, and found that the supply chain system achieves the highest profit under the revenue-sharing contract among the three decentralized contracts (Xiao et al., 2020). Wang et al. (2020) considered the pricing strategies of competing dual-channel retailers, focused on whether and when they should adopt the BOPS strategy, and explored the impacts of market factors on the equilibrium outcomes (Wang et al., 2020).

In summary, the above studies have studied the factors affect the user's know- 
ledge sharing behavior at three levels: cooperation times, interpersonal relationship, experience and other aspects at individual level; the complementary and superposition at knowledge level; incentive and punishment at system level, but they have not considered the dynamic evolution of users' behavior and comprehensive factors. Firstly, most of current research is based on the static perspective but lacks dynamic studies on the user's knowledge sharing behavior in a brand virtual community. Secondly, user's knowledge sharing behavior is affected by multiple level factors including individual, user relationship and community system. Comprehensive factors should be considered in the dynamic evolutionary game of user's knowledge sharing behavior. Therefore, this paper comprehensively analyzes the dynamic various factors on user's knowledge sharing behavior from the aspects of individual factors, reciprocity factors and community factors based on evolutionary game theory.

\section{Methodology}

\subsection{The Process of Knowledge Sharing among Users in Brand Virtual Communities}

Enterprises will set up multiple different knowledge modules on the brand virtual community platform, and users will select appropriate knowledge modules for knowledge exchange according to their own interests and knowledge reserves. The process is shown in Figure 1.

1) Users register and join a brand virtual community platform according to their own interests ( $\mathrm{He} \& \mathrm{Li}, 2015)$, then they will choose to join some modules and share knowledge with other users (Yan \& Ye, 2017).

2) A user posts according to his own knowledge of the brand product (Ruan \& Zhang, 2017), so as to play the role of the knowledge contributor to share his

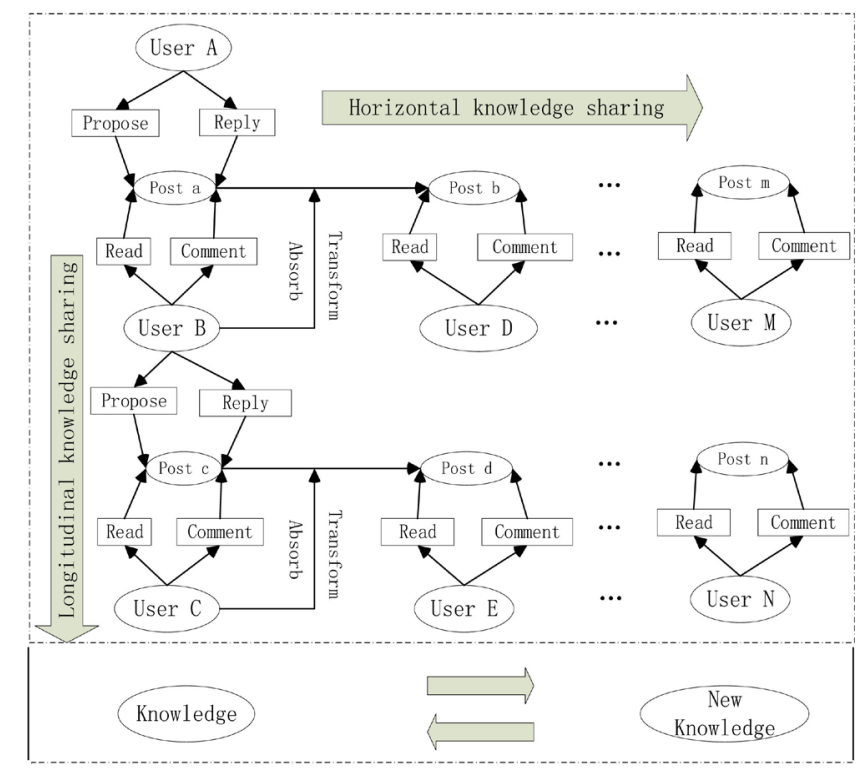

Figure 1. The process of knowledge sharing among users in a brand virtual community. 
own knowledge. Other users read and comment on this post. Some new posts (knowledge) will be created during the communication between users. In this process, more and more new knowledge will be generated, which can be regarded as the horizontal knowledge sharing in Figure 1.

3) Users will publish new posts that they are good at but have nothing to do with the content of the posts as well. The readers of this post will repeat the behavior in (2) for horizontal knowledge sharing, and will also continuously publish new posts that are not related to the content of reading posts. Thus, the continuous continuation of new posts will form the vertical knowledge sharing path in Figure 1.

4) With the continuous continuation of the horizontal knowledge sharing and the vertical knowledge sharing, more and more high-quality new knowledge, such as suggestions and users' needs, will be generated, so that enterprise knowledge base will become more abundant and diverse.

\subsection{System Model}

\subsubsection{Parameters and Assumptions}

The user knowledge sharing process under the brand virtual community platform is a two-way knowledge interaction communication process between participating users. Based on the perspective of participating users' expected benefits in brand virtual communities, an evolutionary game model of user knowledge sharing behavior in brand virtual communities is constructed. The model parameters are explained as shown in Table 1.

1) Direct knowledge sharing income: $\pi_{i}(i=A, B)$ represents the direct income of users when they do not share knowledge in the brand virtual community.

2) $k_{i}(i=A, B), l_{i}(i=A, B), \beta_{i}(i=A, B)$ represent the user's knowledge level, knowledge sharing degree, and knowledge absorption ability. The direct

Table 1. Summary of key parameters.

\begin{tabular}{cl}
\hline Parameters & \multicolumn{1}{c}{ Descriptions } \\
\hline$A$ & User A \\
$\pi_{i}(i=A, B)$ & User B \\
$k_{i}(i=A, B)$ & The direct income to users \\
$l_{i}(i=A, B)$ & The knowledge level of users \\
$\beta_{i}(i=A, B)$ & Knowledge sharing degree of users \\
$h$ & Knowledge absorption ability of users \\
$m$ & Collaborative innovation of knowledge \\
$I_{i}(i=A, B)$ & The homogeneity of knowledge \\
$c$ & Knowledge spillover effect of users \\
$r$ & The total cost of knowledge sharing \\
$e$ & The collaborative profit distribution coefficient \\
& Incentive coefficient \\
\hline
\end{tabular}


income $\pi_{A}$ refers to the benefits obtained by user A after absorbing and transforming user B's shared knowledge to his own knowledge, which is mainly affected by the three factors: $k_{B}, l_{B}$ and $\beta_{A}$. When user B has high $k_{B}$ (user B has a large stock of high-quality knowledge) and high $l_{B}$ (user B has knowledge sharing degree), the higher the probability of $\pi_{A} ;\left(\pi_{A}\right.$ is proportional to $l_{B}$ and $\beta_{A}$, which represent the stronger the user's ability to transform and absorb the other party's shared knowledge), the higher the direct sharing income he will obtain. From the above analysis, it can be seen that the direct income obtained by user $\mathrm{A}$ and user $\mathrm{B}$ in choosing a knowledge sharing strategy in the brand virtual community can be expressed as: $\beta_{A} l_{B} k_{B}, \beta_{B} l_{A} k_{A}$.

3) $h, m, I_{i}(i=A, B)$ respectively represent the collaborative innovation of knowledge, the homogeneity of shared knowledge and the spillover effect. Collaborative benefit refers to the knowledge value increment brought by knowledge fusion due to the difference of knowledge composition when both users share knowledge. The value of collaborative benefit depends on $h$. To some extent, there will be a knowledge overlap between users in the brand virtual community, which is represented by $\mathrm{m}$. And the total amount of synergistic benefits that users obtain from knowledge sharing can be expressed as: $h(1-m)\left(k_{A}+k_{B}\right)$. There is a phenomenon that users "free ride" in the virtual community, in other words, not all users choose to share knowledge. $h_{A}(i=A, B)$ means that the participating users unilaterally share knowledge, and the sharing users can obtain their own innovation benefits as $h_{i} k_{i}$. At the same time, due to the existence of knowledge spillover effects, participating users will obtain a certain spillover effect from the community, which is represented by $I_{i}(i=A, B)$.

4) $C, r$, e represent the total cost of sharing, the collaborative profit distribution coefficient and the incentive coefficient. Users need to pay a certain sharing cost (c) to obtain the sharing income. Besides, the distribution coefficient of collaborative benefits $(r)$ is positively related to the knowledge contribution of participating users. Since knowledge sharing among users in the virtual community is a voluntary behavior, enterprises need to formulate incentive policies (incentive coefficient $e$ ) to encourage community users in knowledge sharing. Then the sharing cost of user A and user B in the virtual community can be expressed as: $(1-e) r c,(1-e)(1-r) c$.

5) Assuming that the probability of user A sharing knowledge is $x(0 \leq x \leq 1)$, the probability of not sharing knowledge $1-x$. Similarly, the probability of user $\mathrm{B}$ choosing a knowledge sharing strategy is $y(0 \leq y \leq 1)$, and probability of not sharing knowledge is $1-y$. According to the related evolutionary game theory, the values of $x$ and $y$ are not fixed, they will change with the changes of the participating users in the community during the learning process. In order to simplify this discussion process, it is assumed that their initial values are constant.

\subsubsection{Game Payout Matrix}

According to the analysis of the above, the game payment matrix of user knowledge sharing behaviors in brand virtual communities is constructed, as shown in Table 2. 
Table 2. Payout matrix of both parties in the game.

\begin{tabular}{|c|c|c|}
\hline User A User B & Knowledge sharing $(y)$ & $\begin{array}{c}\text { No knowledge sharing } \\
(1-y)\end{array}$ \\
\hline $\begin{array}{l}\text { Knowledge } \\
\text { sharing }(x)\end{array}$ & $\begin{array}{c}\pi_{A}+\beta_{A} l_{B} k_{B}+r h(1-m)\left(k_{A}+k_{B}\right)-(1-e) r c \\
\pi_{B}+\beta_{B} l_{A} k_{A}+(1-r) h(1-m)\left(k_{A}+k_{B}\right)-(1-e)(1-r) c\end{array}$ & $\begin{array}{c}\pi_{A}+h_{A} k_{A}-(1-e) r c \\
\pi_{B}+I_{B}\end{array}$ \\
\hline $\begin{array}{l}\text { No knowledge } \\
\text { sharing }(1-x)\end{array}$ & $\begin{array}{c}\pi_{A}+I_{A}, \\
\pi_{B}+h_{B} k_{B}-(1-e)(1-r) c\end{array}$ & $\begin{array}{l}\pi_{A}, \\
\pi_{B}\end{array}$ \\
\hline
\end{tabular}

\subsection{Analysis of the Evolutionarily Stable Strategy}

According to the payment matrix of both sides of the game constructed in Table 2 , we can get the expected revenue of user A if he chooses the knowledge sharing strategy is as follows:

$$
\begin{aligned}
U_{A 1}= & y\left(\pi_{A}+\beta_{A} l_{B} k_{B}+r h(1-m)\left(k_{A}+k_{B}\right)-(1-e) r c\right) \\
& +(1-y)\left(\pi_{A}+h_{A} k_{A}-(1-e) r c\right) \\
= & \pi_{A}-(1-e) r c+h_{A} k_{A}+y\left(\beta_{A} l_{B} k_{B}+r h(1-m)\left(k_{A}+k_{B}\right)-h_{A} k_{A}\right)
\end{aligned}
$$

If participant A does not choose the knowledge sharing strategy, the expected revenue is:

$$
U_{A 2}=y\left(\pi_{A}+I_{A}\right)+(1-y) \pi_{A}=\pi_{A}+y I_{A}
$$

The average income of user $\mathrm{A}$ is:

$$
\begin{aligned}
\bar{U}_{A}= & x U_{A 1}+(1-x) U_{A 2} \\
= & \pi_{A}+y I_{A}+x\left(h_{A} k_{A}-(1-e) r c\right) \\
& +x y\left(\beta_{A} l_{B} k_{B}+r h(1-m)\left(k_{A}+k_{B}\right)-I_{A}-h_{A} k_{A}\right)
\end{aligned}
$$

User A's replicator dynamics equation:

$$
\begin{aligned}
& F(x)=\frac{d_{x}}{d_{t}}=x\left(U_{A 1}-\bar{U}_{A}\right) \\
& =x(1-x)\left(y\left(\beta_{A} l_{B} k_{B}-I_{A}+r h(1-m)\left(k_{A}+k_{B}\right)-h_{A} k_{A}\right)+h_{A} k_{A}-(1-e) r c\right)
\end{aligned}
$$

The stable strategy for replicator dynamics equation needs two conditions: $F\left(x^{*}\right)=0$ and $F^{\prime}\left(x^{*}\right)<0$. When $x$ is biased lower than $x^{*}, F(x)>0$, and when $x$ is biased higher than $x^{*}, F(x)<0$.

Because $F(x)=0$, we can get $x^{*}=0$ or $x^{*}=1$, $y^{*}=\frac{(1-e) r c-h_{A} k_{A}}{\beta_{A} l_{B} k_{B}-I_{A}+r h(1-m)\left(k_{A}+k_{B}\right)-h_{A} k_{A}}$.

1) When $(1-e) r c-h_{A} k_{A}>\beta_{A} l_{B} k_{B}-I_{A}+r h(1-m)\left(k_{A}+k_{B}\right)-h_{A} k_{A}$, that's equal to $I_{A}>\beta_{A} l_{B} k_{B}+r h(1-m)\left(k_{A}+k_{B}\right)-(1-e) r c$. For any $y(0 \leq y \leq 1)$, there is: $F^{\prime}(x=0)<0$, so $x=0$ is the evolutionary stable strategy of the game.

2) When $(1-e) r c-h_{A} k_{A}<\beta_{A} l_{B} k_{B}-I_{A}+r h(1-m)\left(k_{A}+k_{B}\right)-h_{A} k_{A}$, which is equal to $I_{A}<\beta_{A} l_{B} k_{B}+r h(1-m)\left(k_{A}+k_{B}\right)-(1-e) r c$, If $y>y^{*}$, that is 
$F^{\prime}(x=1)<0$. At this time, $x=1$ is the evolutionary stable strategy of the game. If $y<y^{*}, F^{\prime}(x=0)<0$, and then $x=0$ is the evolutionary stable strategy of the game. In this case, the evolutionary stability strategy is jointly affected by the initial sharing probability $y$ and the critical value $y^{*}$. When the value of $y^{*}$ is higher, the possibility that $y$ exists in the interval $\left[0, y^{*}\right]$ is greater, and the stable strategy of participating users in the virtual community will evolve in the direction of not sharing knowledge.

Similarly, the replicator dynamics equation of user B is:

$$
\begin{aligned}
F(y)= & \frac{d_{y}}{d_{t}}=y\left(U_{B 1}-\bar{U}_{B}\right) \\
= & y(1-y)\left(x\left(\beta_{B} l_{A} k_{A}-I_{B}+(1-r) h(1-m)\left(k_{A}+k_{B}\right)-h_{B} k_{B}\right)\right. \\
& \left.+h_{B} k_{B}-(1-e)(1-r) c\right)
\end{aligned}
$$

As $F(y)=0$, we can get: $y=0$ or $y^{*}=1$,

$x^{*}=\frac{(1-e)(1-r) c-h_{B} k_{B}}{\beta_{B} l_{A} k_{A}-I_{B}+(1-r) h(1-m)\left(k_{A}+k_{B}\right)-h_{B} k_{B}}$.

3) When $(1-e)(1-r) c-h_{B} k_{B}>\beta_{B} l_{A} k_{A}-I_{B}+(1-r) h(1-m)\left(k_{A}+k_{B}\right)-h_{B} k_{B}$, that equal to $I_{B}>\beta_{B} l_{A} k_{A}+(1-r) h(1-m)\left(k_{A}+k_{B}\right)-(1-e)(1-r) c$. For any $x(0 \leq x \leq 1), F^{\prime}(y=0)<0$, and so $y=0$ is the evolutionary stable strategy of the game.

4) When $(1-e)(1-r) c-h_{B} k_{B}<\beta_{B} l_{A} k_{A}-I_{B}+(1-r) h(1-m)\left(k_{A}+k_{B}\right)-h_{B} k_{B}$, that equal to $I_{B}<\beta_{B} l_{A} k_{A}+(1-r) h(1-m)\left(k_{A}+k_{B}\right)-(1-e)(1-r) c$. If $x>x^{*}$, that is $F^{\prime}(y=1)<0, y=1$ is the evolutionary stable strategy of the game. If $x<x^{*}$, then $F^{\prime}(y=0)<0, y=0$ is the evolutionary stable strategy of the game. In this case, the evolutionary stability strategy is jointly affected by the initial shared probability $x$ and the critical value $x^{*}$. When the value of $x^{*}$ is higher, the possibility that $x$ exists in the interval $\left[0, x^{*}\right]$ is greater, and the stability strategy of participating users in the virtual community will evolve in the direction of not sharing knowledge.

The situation of users may change at any time in the brand virtual community, it is necessary to take the situation of user A and user B into the evolutionary game. The evolutionary stability strategy formed by the interaction between user $A$ and user $B$ can be discussed in the following situations:

I) When user A and user B choose the strategies (1) and (3) respectively, user $A$ and user $B$ find that the benefits obtained by not choosing the knowledge sharing strategy are better than those obtained by knowledge sharing. The evolution system will converge to the point $O(0,0)$ through constantly learning, as shown in Figure 2.

II) When user A and user B choose the strategies (1) and (4) respectively, as shown in Figure 3, the knowledge sharing path trend of user $A$ and user $B$ presents an inverted $U$ shape. Because user B tends to choose the knowledge sharing strategy at the beginning, the probability of user B sharing knowledge will gradually increase. Considering its own interests, user A thinks that not sharing knowledge is the optimal strategy. In the process of evolution, user A 


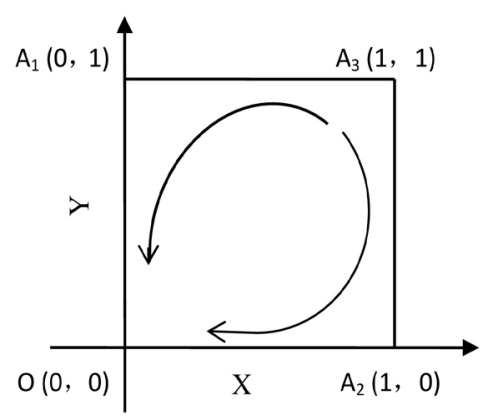

Figure 2. The dynamic evolution diagram of user knowledge sharing (case I).

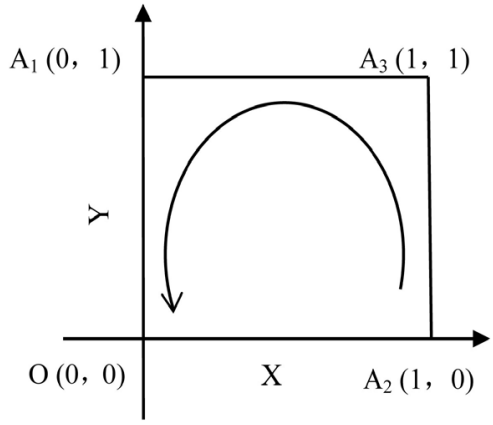

Figure 3. The dynamic evolution diagram of user knowledge sharing (case II).

will constantly adjust the strategy to the path of no knowledge sharing. With the continuous development of user's game behavior, user B will also find that the probability of knowledge sharing will gradually decrease if he does not share knowledge. With the passage of time and the continuous learning of users, the system finally converges to the point $O(0,0)$.

III) When user A and user B select the strategies (2) and (3) respectively, as shown in Figure 4, the knowledge sharing path trend of user $A$ and user $B$ presents a side $U$ shape. Because user A initially selects the knowledge sharing strategy as its optimal strategy, the probability of knowledge sharing of user A in the virtual community will gradually rise. Based on his own interests, user B believes that not sharing knowledge is his optimal strategy. During the evolution process, he will continuously adjust his strategy to evolve in the path of not sharing knowledge. With the continuous progress of the game, user A will also find that if he does not share knowledge, he will get relatively higher benefits, and his probability of knowledge sharing will gradually decrease. As time goes on, the system will eventually converge to the point $O(0,0)$.

IV) When user A and user B select the strategies (2) and (4) respectively, as shown in Figure 5.

If $I_{A}<\beta_{A} l_{B} k_{B}+r h(1-m)\left(k_{A}+k_{B}\right)-(1-e) r c$ and $I_{B}<\beta_{B} l_{A} k_{A}+(1-r) h(1-m)\left(k_{A}+k_{B}\right)-(1-e)(1-r) c$, that is, (knowledge sharing, knowledge sharing) and (no knowledge sharing, no knowledge sharing) are the evolutionary stable state of the system. When we located in the area $O A_{1} A_{2} A_{4}$, the probability of knowledge sharing between user $\mathrm{A}$ and user $\mathrm{B}$ will 


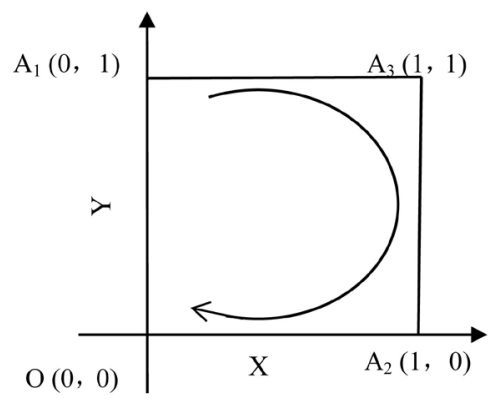

Figure 4. The dynamic evolution diagram of user knowledge sharing (case III).

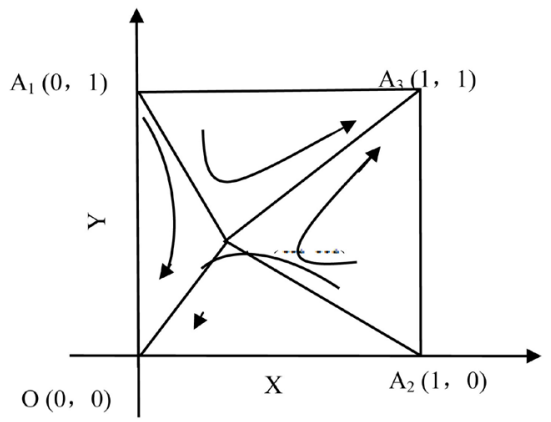

Figure 5. The dynamic evolution diagram of user knowledge sharing (case IV).

decrease and finally converge to the point $O(0,0)$, which means the system will evolve in the direction of (no knowledge sharing, no knowledge sharing). When we located in the area of $A_{1} A_{2} A_{3} A_{4}$, the probability of knowledge sharing between user $\mathrm{A}$ and user $\mathrm{B}$ in the brand virtual community will increase, and finally converge to the point $A_{4}(1,1)$, which means the system will evolve in the direction of (knowledge sharing, knowledge sharing)

There are 5 local equilibrium points: $O(0,0), A_{1}(0,1), A_{2}(1,0), A_{3}(1,1)$, $A_{4}\left(X^{*}, Y^{*}\right)$ in the system. Point $O(0,0)$ and $A_{3}(1,1)$ are evolutionary stable points, but point $A_{1}(0,1)$ and $A_{2}(1,0)$ are unstable points, and point $A_{4}$ is the saddle point. $A_{4}\left(X^{*}, Y^{*}\right)$ is the key point that affects the game results. The higher the value of $A_{4}$, the larger the area of $O A_{1} A_{2} A_{4}$, and the lower probability of users choose to share knowledge; The lower the value of $A_{4}$, the larger the area of $A_{1} A_{2} A_{3} A_{4}$, and the higher probability of users will choose knowledge sharing.

And we get:

$$
\begin{aligned}
x^{*} & =\frac{(1-e)(1-r) c-h_{B} k_{B}}{\beta_{B} l_{A} k_{A}-I_{B}+(1-r) h(1-m)\left(k_{A}+k_{B}\right)-h_{B} k_{B}}, \\
y^{*} & =\frac{(1-e) r c-h_{A} k_{A}}{\beta_{A} l_{B} k_{B}-I_{A}+r h(1-m)\left(k_{A}+k_{B}\right)-h_{A} k_{A}}
\end{aligned}
$$

\section{Numerical Simulation Analysis}

The evolutionary path of knowledge sharing behavior among users in the brand virtual community is closely related to the parameters of game payoff matrix. In 
order to describe the influence of each parameter change on the user's knowledge sharing strategy, this paper uses MATLAB to simulate the data.

We assume user's knowledge reserve level is $k_{i} \in[100,200]$, the knowledge sharing degree between users is $l_{i} \in[0.25,1]$, the user's knowledge absorption ability is $\beta_{i} \in[0.25,1]$, the homogeneity of knowledge is $m \in[0.2,0.8]$, user's sharing cost is $c \in[100,200]$, the distribution coefficient is $r \in[0.2,0.8]$, the spillover effect is $I_{i} \in[20,60]$, the collaborative innovation coefficient is $h \in[0.4,1]$, and the incentive coefficient is $e \in[0.2,0.8]$.

1) The impact of knowledge reserves on the probability of sharing

Under the assumption that other parameters are constant, the influence of the change of knowledge reserve on the sharing probability is shown in Figure 6. The probability of user A and user B choosing the knowledge sharing strategy increases with the increase of user's knowledge reserve level. With the improvement of user's knowledge reserve level on both sides, the benefits obtained after knowledge sharing and exchange will increase, and the willingness of user $\mathrm{A}$ and user B to share knowledge will become stronger.

2) The influence of the degree of knowledge sharing and the ability of knowledge absorption on the probability of sharing

Under the assumption that other parameters remain unchanged, the influence is shown in Figure 7. When the degree of knowledge sharing gradually increases from 0.25 to 1 , the probability of user $\mathrm{A}$ and user $\mathrm{B}$ choosing the knowledge sharing behavior also increases. When user $\mathrm{A}$ has a high degree of knowledge sharing, user B will obtain greater revenue if he chooses the knowledge sharing strategy. When the knowledge absorption abilities of users increase from 0.25 to 1 , the probability of user A and user B choosing the knowledge sharing behavior will increase accordingly. The area of $s_{1}$ gradually decreases but the area of $s_{2}$ gradually increases. When the participating users' ability to absorb knowledge becomes stronger, the revenue will increase. In this case, the possibility of stable strategy (knowledge sharing, knowledge sharing) will gradually increase.

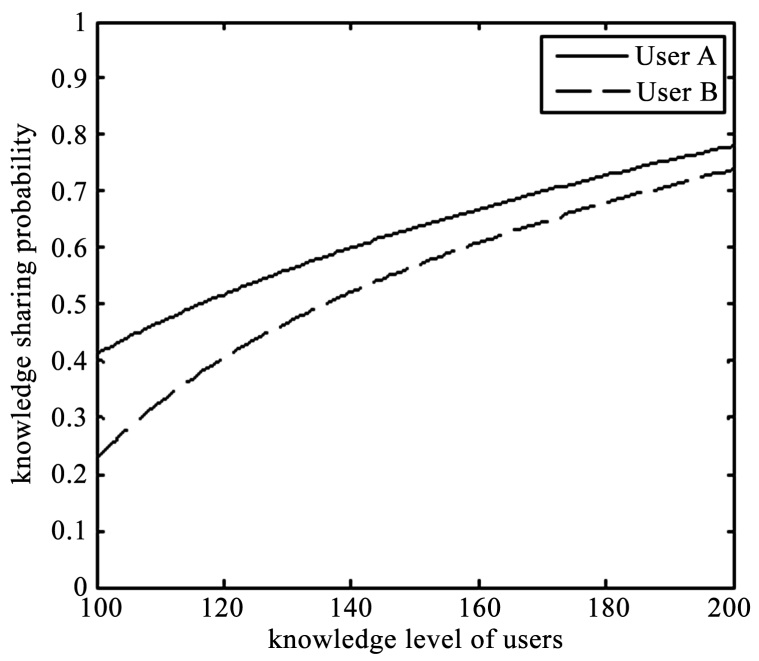

Figure 6. The impact of users' knowledge reserves on the sharing probability. 


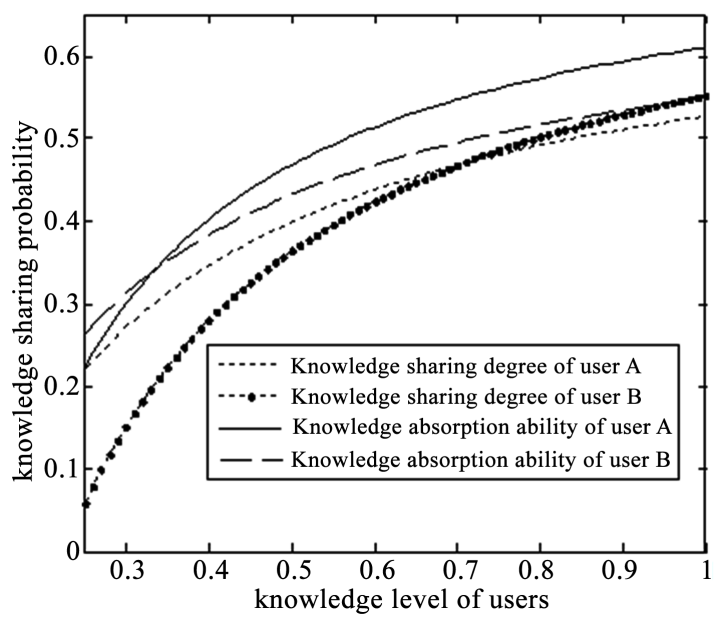

Figure 7. The influence of users' knowledge absorption ability and knowledge sharing degree on the sharing probability.

3) The impact of the cost of knowledge sharing on the probability of sharing

Under the premise of assuming that other parameters remain unchanged, when the sharing cost of both sides in the game changes in the interval [100, 200], the simulation results are shown in Figure 8. As the cost of participating users' knowledge sharing increases, the probability of choosing the knowledge sharing strategy of both sides decrease. The area of $s_{1}$ increases but the area of $s_{2}$ continues to decrease. That is because as the cost of participating users' knowledge sharing increases, the benefits of participating users' knowledge sharing become smaller. In this case, the possibility of stable strategy (knowledge sharing, knowledge sharing) will decrease.

4) The influence of homogeneity of knowledge sharing, the distribution coefficient and incentive coefficient on the probability of sharing

It can be seen from Figure 9, as the homogeneity of knowledge sharing increases, the probability of both participating users choosing the knowledge sharing strategy continues to decrease. With the increase of knowledge overlapping degree, the possibility of users to acquire new knowledge becomes smaller, and that cause the system evolves to stable strategy (knowledge sharing, knowledge sharing) with a small probability.

As the distribution coefficient increases, the curve gradually decreases. When it decreases to a certain level, the curve gradually rises with the increase of the distribution coefficient. There is a minimum in the whole process, which is an optimal co-income distribution coefficient makes the area $s_{1}$ smallest and the area $s_{2}$ largest. It shows that a reasonable distribution coefficient based on the knowledge contribution will encourage users to share knowledge.

The increase of the incentive coefficient will increase the probability of both users choosing the knowledge sharing strategy. Because the greater the incentive provided by the enterprise, the more revenue obtained by user for knowledge sharing, and that cause the system evolve towards strategy (knowledge sharing, knowledge sharing). 


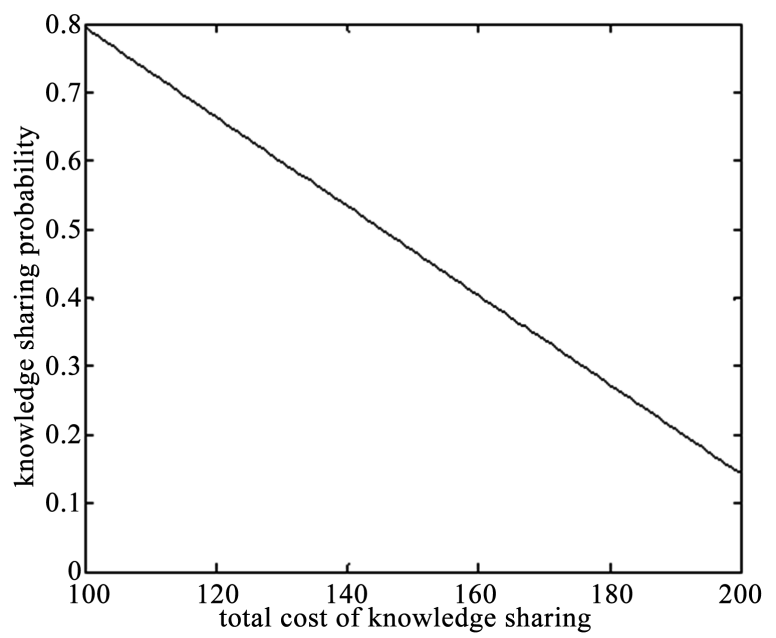

Figure 8. The impact of users' knowledge sharing costs on the sharing probability.

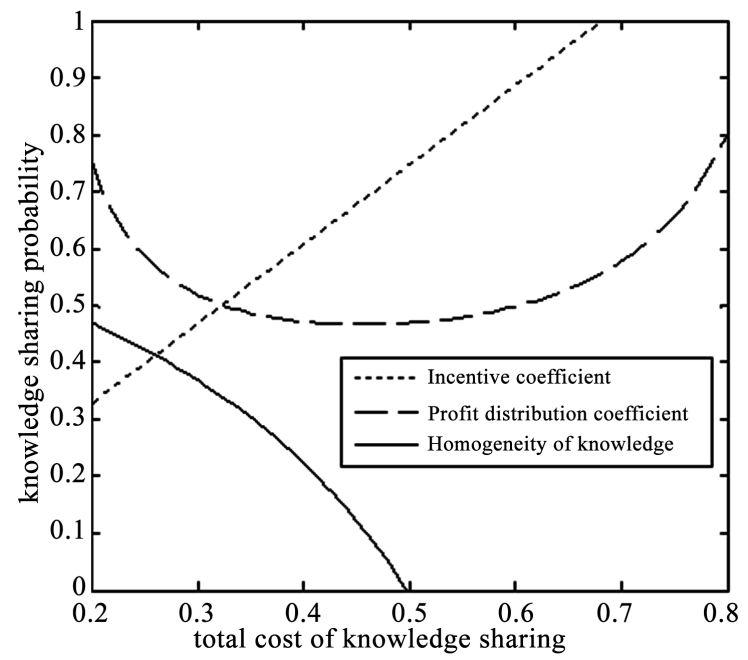

Figure 9. The influence of homogeneity of knowledge sharing, the distribution coefficient and incentive coefficient on the probability of sharing.

5) The impact of collaborative innovation coefficient on the sharing probability

The possibility of both parties in the game choosing the knowledge sharing strategies increases with the increase of the co-innovation coefficient, indicating that the area of $s_{1}$ decreases, and the area of $s_{2}$ increases. When only one party chooses the strategy of sharing knowledge, the sharing probability increases with the increase of the innovation coefficient, which is shown in Figure 10.

6) The impact of spillover effects on sharing probability

It can be seen from Figure 11 that with the enhancement of users' spillover effect, the probability of both participating users choosing the knowledge sharing strategy is continuously decreasing. The reason is that as the spillover effect of participating users increases, users will gain greater benefits without participating in knowledge sharing. In this case, the participating users in the game will choose the strategy of not sharing knowledge with a greater probability. 


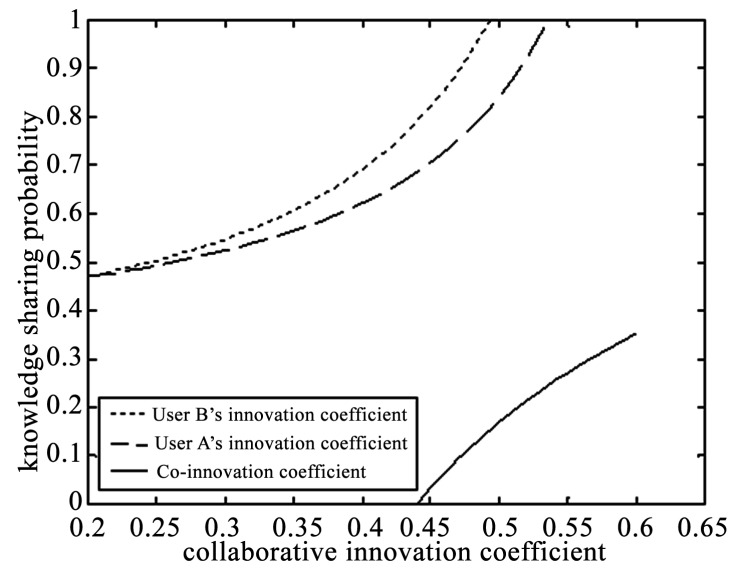

Figure 10. The impact of collaborative innovation coefficient on the sharing probability.

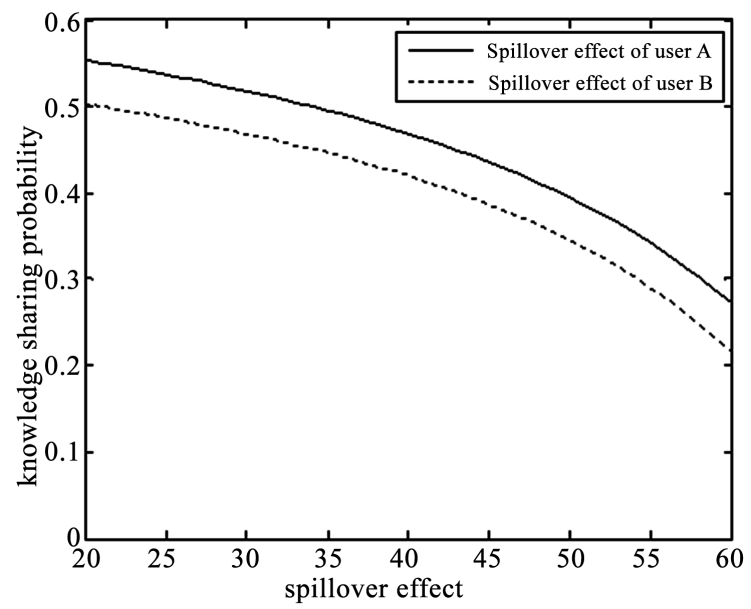

Figure 11. The impact of the spillover effect of knowledge sharing on the probability of sharing.

\section{Conclusion}

This paper establishes an evolutionary game model of user knowledge sharing in brand virtual communities, and analyzes the influence of personal factors, reciprocity factors, and community factors on the knowledge sharing behavior between users through numerical simulation. The research results show that:

1) There are two evolutionary stable strategies for participating in the user knowledge sharing game, namely (knowledge sharing, knowledge sharing) and (no knowledge sharing, no knowledge sharing). In this case, which direction the system evolves to, depends on the initial probability and critical point of user knowledge sharing.

2) Through the research and simulation analysis of the influence factors of the user's knowledge sharing behavior in the brand virtual community, it is found that: the knowledge level of users, the knowledge absorption ability of users, the degree of knowledge sharing and the degree of knowledge innovation in individual level and the incentive coefficient in community level have a positive impact on user's knowledge sharing behavior. But the sharing cost in individual 
level, the homogeneity of shared knowledge and the spillover effect in mutual level have a negative impact on user's knowledge sharing behavior.

3) In the process of user knowledge sharing, there is an optimal collaborative profit distribution coefficient, which maximizes the probability of the system evolving in the direction of (knowledge sharing, knowledge sharing).

4) Enterprise virtual community needs to set reasonable incentive coefficient and collaborative income distribution coefficient, and give users flexible rewards according to the contribution degree of participating users, instead of a fixed reward strategy, which is conducive to improving the enthusiasm of the participants in knowledge sharing.

Despite of the promising outcomes of knowledge sharing presented by this paper, there are still some limitations which can be addressed in future research. Firstly, there are so many factors influencing users' feelings. At present, the academia has not yet reached a consensus on the factors affecting the user's knowledge sharing behavior in the enterprise virtual community. In this paper, only a part of important factors are selected to study. Secondly, although the numerical simulation of the model is carried out, there is a lack of an actual case to illustrate. Based on the above defects in this paper, we can further optimize and expand the model in the future research, such as increasing the game subject to three or more, and combining the mathematical model with the actual case, which will get more convincing conclusions.

\section{Acknowledgements}

The work was supported by the National Nature Science Foundation of China [Grant No. 71761012] and the Humanities and Social Sciences Plan of Jiangxi Province, China [Grant No. GL20135].

\section{Author Contributions}

Conceptualization, C. L.; Methodology, Y. Z. and C. L.; Writing-Original Draft Preparation, Y. Z. and C. L.; Writing-Review and Editing, C. L. P. L. and Y. Z.; Model Analysis, P. L.; Investigation, P. L. and Y. Z.

\section{Conflicts of Interest}

The authors declare no conflict of interest.

\section{References}

Casandra, F., Debra, G., Bill, M. et al. (2018). Customer Brand Co-Creation Behavior: Conceptualization and Empirical Validation. Marketing Intelligence Planning, 36, 334-348. https://doi.org/10.1108/MIP-10-2017-0266

Chen, L., Nan, G. F., \& Li, M. Q. (2018). Wholesale Pricing or Agency Pricing on Online Retail Platforms: The Effects of Customer Loyalty. International Journal of Electronic Commerce, 22, 576-608. https://doi.org/10.1080/10864415.2018.1485086

Cheng, H. P., Xiao, W., \& Cheng, Y. Q. (2018). Evolutionary Game Analysis on User Adoption Behavior of Personal Cloud Service. Research on Library Science, 5, 51-57. 
Gu, M. L., Chi, M., \& Han, J. P. (2019). Research on the Impact of Open Innovative Community Governance Mechanism on User Knowledge Contribution BehaviorBased on the Mediating Effect of Virtual Community Sense. Science Technology Progress and Policy, 36, 30-37.

Han, Z. T., Zhang, W. Y., \& Hu, B. (2019). Dual Roles of Users in Online Brand Community and Knowledge Sharing Behavior: A Simulation Study. Kubernetes, 48, 2093-2116. https://doi.org/10.1108/K-07-2018-0409

Hao, C. C., Du, Q., \& Huang, Y. D. et al. (2019). Evolutionary Game Analysis of Knowledge Sharing Behavior among Members of Technology Innovation Alliance. Sustainability, 19, 5319. https://doi.org/10.3390/su11195319

He, A. Z., \& Li, X. (2015). A Study on the Evolutionary Mechanism of Motivations in the Formation of Online Brand Community Members' Sustained Participation Behavior. Chinese Journal of Management, 12, 733-743.

Hou, G. S., Wang, P. M., \& Yang, L. (2017). Research on Evolutionary Game of the Knowledge Conversion and Sharing of Online Health Community Users. Information Science, 35, 31-38.

Hwang, Y., Lin, H., \& Donghee, S. (2018). Knowledge System Commitment and Knowledge Sharing Intention: The Role of Personal Information Management Motivation. International Journal of Information Management, 39, 220-227.

https://doi.org/10.1016/j.ijinfomgt.2017.12.009

Jakob, N. (2014). Participation Inequality: Encouraging More Users to Contribute. http://www.nngroup.com/articles/participation-inequality

Jiang, G., Ma, F., Shang, J. et al. (2014). Evolution of Knowledge Sharing Behavior in Social Commerce: An Agent-Based Computational Approach. Information Sciences, 278, 250-266. https://doi.org/10.1016/j.ins.2014.03.051

Li, M. W., Jia, S. L., \& Du, W. Y. (2019). Fans as a Source of Extended Innovation Capabilities: A Case Study of Xiaomi Technology. International Journal of Information Management, 44, 204-208. https://doi.org/10.1016/j.ijinfomgt.2018.09.007

Li, Q., \& Kang, Y. (2019). Knowledge Sharing Willingness and Leakage Risk: An Evolutional Game Model. Sustainability, 11, 596. https://doi.org/10.3390/su11030596

Li, W. Y., Zhai, X. X., \& Xu, F. (2018). Research of the Impact of Interpersonal Relationship Motivation on Knowledge Sharing Behavior in Visual Brand Communities: A Moderated Mediation Model. Management Review, 30, 89-99.

Liao, J. Y., Huang, M. X., Peng, J. et al. (2017). The Relationship between Firms' Virtual Brand Community Engagement Activities and Consumers' Community Commitment. Management Review, 29, 73-83.

Liu, C., \& Liu, X. (2019). Research on Knowledge Transfer Behavior in Cooperative Innovation and Simulation. Economic Research-Ekonomsk Istrazivanja, 32, 1219-1236. https://doi.org/10.1080/1331677X.2019.1627895

Meng, Q. L., Hang, Y., \& Chen, X. J. (2019). User Roles in Virtual Community of Crowdsourcing for Innovation: A Case Study of Xiaomi MIUI in China. Tehnicki Vjesnik-Technical Gazette, 26, 1392-1399. https://doi.org/10.17559/TV-20190627120336

Meng, Q., Zhang, Z., Wan, X. et al. (2018). Properties Exploring and Information Mining in Consumer Community Network: A Case of Huawei Pollen Club. Complexity, 1-19. https://doi.org/10.1155/2018/9470580

Nielsen, J. (2006). Participation Inequality: Encouraging More Users to Contribute. Quaderns De Filologia Estudis Literaris, 2688, 11-25.

Park, J., \& Gabbard, J. L. (2018). Factors That Affect Scientists' Knowledge Sharing Beha- 
vior in Health and Life Sciences Research Communities: Differences between Explicit and Implicit Knowledge. Computers in Human Behavior, 78, 326-335.

https://doi.org/10.1016/j.chb.2017.09.017

Porter, C. E., Donthu, N., MacElroy, W. H. et al. (2011). How to Foster and Sustain Engagement in Virtual Communities. California Management Review, 53, 80-110. https://doi.org/10.1525/cmr.2011.53.4.80

Ruan, P. N., \& Zhang, Y. Q. (2017). Research on User Demand Identification Based on Open Innovation Community-Taking Millet Community as an Example. Soft Science, 31, 20-24.

Shang, S. X., \& Zhang, Z. S. (2015). The Knowledge Sharing of Virtual Enterprise Based on Evolutionary Game. China Soft Science, No. 3, 150-157.

Shen, X. L., \& Li, Y. J. (2018). Knowledge Contribution in Virtual Brand Community: Integrating Person-Environment Fit and Self-Determination Theory. Management Review, 30, 82-94.

Shen, X., \& Chen, C. B. (2019). The Impact of Government Behavior on the Coordinated Development of Financial Business with Supply Chain-Based on the Evolutionary Game Theory. Journal of Technical Economics, Management, No. 2, 81-85.

Tian, Y. H., Govindan, K., \& Zhu, Q. H. (2014). A System Dynamics Model Based on Evolutionary Game Theory for Green Supply Chain Management Diffusion among Chinese Manufacturers. Journal of Cleaner Production, 80, 96-105. https://doi.org/10.1016/j.jclepro.2014.05.076

Wang, R. H., Nan, G. F., Chen, L., \& Li, M. Q. (2020). Channel Integration Choices and Pricing Strategies for Competing Dual-Channel Retailers. IEEE Transactions on Engineering Management, No. 7, 1-15. https://doi.org/10.1109/TEM.2020.3007347

Wirtz, J., Den Ambtman, A., Bloemer, J. et al. (2013). Managing Brands and Customer Engagement in Online Brand Communities. Journal of Service Management, 24, 223-244. https://doi.org/10.1108/09564231311326978

Xiao, Q. Z., Chen, L., Xie, M., \& Wang, C. (2020). Optimal Contract Design in Sustainable Supply Chain: Interactive Impacts of Fairness Concern and Overconfidence. Journal of the Operational Research Society, No. 2, 1-20. https://doi.org/10.1080/01605682.2020.1727784

Yan, B. N., \& Ye, Z. Y. (2017). Research on the Influencing Mechanism of Environmental Factors on User Knowledge Sharing Behavior in Virtual Communities. Information Studies: Theory, Application, 40, 74-79.

Yan, J. Y., Qiao, Y. F., Qing, F. et al. (2019). Research on Value Co-Creation of Customer at Different Levels in Product Innovation Community-A Case Study on MIUI Community. Management Review, 31, 58-70.

Zhang, J. M., Zhu, Q. B., \& Wang, Y. P. (2019). Social Capital on Consumer Knowledge-Sharing in Virtual Brand Communities: The Mediating Effect of Pan-Family Consciousness. Sustainability, 11, 339. https://doi.org/10.3390/su11020339

Zhang, P. H., Zhang, L. Q., \& Hu, S. Q. (2018). Study on the Behavior of Counterfeiter and Regulators Based on Evolutionary Game. Economy and Management, 32, 76-82.

Zhang, X. S., \& Li, X. G. (2017). A Study on the Impact of Virtual Brand Community Characteristic on Consumers' Value Co-Creation Willingness-Explanation Based on the Mediating Role of Satisfaction and Trust. China Business and Market, 31, 70-82.

Zhao, L., Feng, C. M., \& Wang, R. H. (2017). Research on the Evolution Mechanism of Users' Knowledge Sharing Motivation in Enterprise Virtual Community. Information Studies: Theory, Application, 40, 96-100. 
https://doi.org/10.1051/matecconf/201710005006

Zheng, J., Liu, R. J., \& Feng, Y. J. (2018). Impact of Customer Participation on Technological Innovation Performance in the Virtual Brand Community Environment: Regulating the Learning Ability of the Organization. Science of Science and Management of S. \&T., 39, 82-95. 